\title{
SER, TER OU ESTAR? UMA ANÁLISE DO COMPORTAMENTO DO RECIFENSE QUANTO À PRÁTICA DO CONSUMO CONSCIENTE
}

\author{
BEING SENSIBLE, HAVING CONSCIOUSNESS OR BEING \\ CONSCIOUS? AN ANALYSIS OF THE BEHAVIOR OF RECIFE \\ HABITANTS CONCERNING THE CONSCIOUS CONSUMPTION
}

Data de submissão: 06/01/2015 Aceite: $27 / 10 / 2015$

Minelle Enéas da Silva ${ }^{1}$ Natália Mary Oliveira de Souza² Jaqueline Guimarães Santos ${ }^{3}$

\section{RESUMO}

A compreensão do comportamento de consumo pode auxiliar os atores sociais e a própria sociedade, por meio do fornecimento de informações importantes, a desenvolver propostas de conscientização em relação ao consumo e à consequente mudança de atitudes dos indivíduos. Tendo isso em vista, com o objetivo de analisar o comportamento da população do Recife, Pernambuco, quanto à prática do consumo consciente, este estudo, conduzido como survey, pesquisou 601 respondentes das diferentes Regiões Político-Administrativas (RPAs) da cidade. A partir de uma análise estatística, os resultados indicam que o recifense não apresenta ter consciência em seus comportamentos, mas assume uma posição de estar consciente, precisando de uma estrutura organizada para que isso ocorra, o que indica ser necessária a atuação de outros atores que consigam estimular uma mudança, contribuindo com a perspectiva do desenvolvimento sustentável.

Palavras-chave: Consumo Consciente. Comportamento. Desenvolvimento Sustentável.

\footnotetext{
${ }^{1}$ Possui graduação em Administração pela Universidade Federal de Campina Grande, UFCG, mestrado em Administração pela Universidade Federal de Pernambuco, UFPE e doutorado em andamento em Administração pela Universidade Federal do Rio Grande do Sul, UFRGS. Porto Alegre. Rio Grande do Sul, Brasil. E-mail: minele.adm@gmail.com

2 Possui graduação em administração de empresas pela Universidade Federal de Pernambuco, UFPE e mestrado em Administração pela Universidade Federal de Pernambuco, UFPE. Recife. Pernambuco. Brasil. E-mail: natalia.o.souza@gmail.com

${ }^{3}$ Possui graduação em Administração pela Universidade Federal de Campina Grande, UFCG e mestrado em Administração pela Universidade Federal de Pernambuco, UFPE. Caruaru. Pernambuco. Brasil. E-mail: jsantos.adm@gmail.com
} 


\begin{abstract}
The consumption behavior of the population can help both social actors and society itself to understand important information for the development of consumption awareness proposals and the consequent change of individual attitudes. Based on this perspective, this paper aims to analyze the behavior of Recife habitants (Brazil) regarding the conscious consumption through a quantitative approach. Thus, it is possible to present the main features of conscious consumption towards highlighting the contributions to sustainable development. Conducted from a survey, were researched 601 habitants in each Political-Administrative Regions of the city. From a statistical analysis, the results demonstrate that the Recife habitants did not Having consciousness in their behaviors, but they assume Being conscious requiring a best social structure, indicating the need of others social actors action to stimulate a change. All this aspects show that consumer can not contribute with the sustainable development.
\end{abstract}

Keywords: Conscious Consumption. Behavior. Sustainable Development.

\title{
1 INTRODUÇÃO
}

As recentes discussões concernentes às questões ambientais, econômicas e sociais têm demonstrado que as estratégias nacionais e globais, anteriormente focadas no crescimento econômico, necessitam ser reestruturadas como forma de contribuir para um paradigma alternativo de desenvolvimento. Nessa perspectiva, emerge a necessidade de observar um modelo de desenvolvimento que busque adequar dimensões básicas para uma visão sustentável preocupando-se com a relação intergeracional. Para tanto, deve-se buscar o equilíbrio entre as dimensões ambiental, social e econômica, providenciando qualidade de vida para a população sem prejuízo às futuras gerações (ELKINGTON, 2001; SACHS, 2007).

O alcance do desenvolvimento sustentável consiste, assim, em um desafio para a humanidade, uma vez que fatores como pobreza, poluição, tecnologia e diferentes formas de vida estão presentes e exigem mudanças de comportamentos na maneira de agir, pensar, produzir e consumir da sociedade. A mudança de atitude por parte da sociedade é importante porque o desenvolvimento sustentável parte de uma concepção sistêmica, abrangendo questões ambientais, tecnológicas, econômicas, culturais e políticas, as quais apresentam notável complexidade em sua aplicação e, dessa forma, necessitam de reestruturações nos comportamentos de diferentes atores (FRANCO, 2001).

Sob essa perspectiva, um grupo de atores sociais, a exemplo de governo, organizações com e sem fins lucrativos e consumidores, deve atuar nesse processo de mudança, partindo do princípio de que os atuais padrões de produção e de consumo estão nas raízes dos problemas ambientais e sociais (BARBIERI; DIAS, 2002). Nesse sentido, nota-se um interesse das organizações no que diz respeito ao debate acerca das estratégias responsáveis, levando essas organizações a considerarem o interesse dos consumidores por questões sociais e ecológicas, as quais compõem o contexto das relações de troca da nova ordem econômica (ROMEIRO, 2006).

Essa nova ordem econômica reflete uma maior consciência dos consumidores, que se mostram preocupados com suas escolhas, dando preferência a produtos socialmente justos e ecologicamente corretos e, muitas vezes, punindo as empresas que não se preocupam com esses aspectos. De acordo com Santos et al. (2008), atualmente existe uma discussão maior quanto ao consumidor consciente, isto é, àquele que visa transformar o ato de consumir em um ato de cidadania, por meio de uma mudança no seu perfil de consumo (SEYFANG, 2006). Esse consumidor busca, no ato de consumir, equilibrar o seu bem-estar pessoal com o impacto de seu consumo no meio ambiente e com o bem-estar da sociedade. 
Compreende-se que existem dificuldades para a incorporação desse comportamento de consumo, uma vez que: o comportamento é influenciado pelos custos da internalidade dos impactos ambientais e sociais, que provavelmente serão repassados aos preços dos produtos; existem motivações psicológicas e sociológicas e outras influências no consumo, como acessibilidade, disponibilidade, conveniência e identidade; e a percepção da magnitude de seus problemas (e a consideração dos demais) implica mudança individual, que rompe com sentimentos como o egoísmo, por exemplo (DOBSON, 2003). Nesse contexto, podem ser considerados três níveis de consumo consciente: ser consciente (prática inerente ao ser humano), estar consciente (preocupações individuais e pontuais com os impactos no meio) e ter consciência (efetiva reflexão e prática sobre sua atuação no meio e preocupação com a coletividade) (SILVA; MENK, 2014).

Entretanto, percebe-se, na sustentabilidade global, o caminho para o alcance da melhor qualidade de vida e garantia de que as gerações futuras tenham as mesmas condições de sobrevivência. Assim, considerando a possibilidade de atuação de diferentes atores sociais ao assumir suas responsabilidades, dentre os quais estão os indivíduos enquanto consumidores, no que tange ao alcance de uma sociedade pautada nas diretrizes do desenvolvimento sustentável, este estudo tem como objetivo analisar o comportamento da população do Recife quanto à prática do consumo consciente. Para tanto, tem-se como objetivos específicos: determinar o perfil dos entrevistados; apontar características da população recifense quanto à ideia de consumo consciente; verificar se fatores como gênero, escolaridade e renda influenciam a conscientização da população quanto à prática do consumo sustentável; e identificar possíveis contribuições dos consumidores recifenses no que concerne à busca pela mudança rumo ao desenvolvimento sustentável.

Esta pesquisa se justifica na medida em que a compreensão do comportamento de uma população, no que diz respeito às práticas de consumo consciente, pode facilitar a atuação de outros atores sociais no estímulo à mitigação da degradação ambiental advinda do consumo e ao reconhecimento de uma nova perspectiva na sociedade que pode ser efetivada. Em se tratando do consumo entre os recifenses, segundo dados da Federação do Comércio de Bens, Serviços e Turismo do Estado de Pernambuco (Fecomércio-PE) (2014), o índice de Confiança do Consumidor Recifense (ICC) aponta um aumento da credibilidade na economia, o que tende a induzir uma elevação no consumo. Tendo em vista o potencial de crescimento do consumo na capital pernambucana, torna-se ainda mais urgente estudar o consumo consciente dos recifenses.

Para isso, este estudo está estruturado em quatro partes, além desta introdutória. $\mathrm{Na}$ segunda seção, apresenta-se a discussão teórica que embasa o entendimento do fenômeno estudado, na qual são abordados os temas: desenvolvimento sustentável, consumo consciente e comportamento do consumidor. Posteriormente, discorre-se sobre os procedimentos metodológicos com detalhamento das análises estatísticas empregadas. Em seguida, apresentam-se e discutem-se os resultados. Por fim, são expostas as considerações finais.

\section{APORTE TEÓRICO}

\subsection{Desenvolvimento sustentável}

Ao longo dos últimos anos, a sociedade vem crescendo em meio a um modelo de desenvolvimento regido pelo sistema capitalista, preocupando-se apenas com a elevação dos índices econômicos, além de considerar que as fontes de matérias-primas são inesgotáveis e que o planeta tem condições de assimilar os resíduos gerados indefinidamente. Contudo, há problemas econômicos, sociais e, principalmente, ambientais resultantes desse modelo, sendo, então, ne- 
cessária a implantação de um estilo de desenvolvimento que contemple uma visão macro considerando que os recursos são finitos.

Nesse contexto, surge o desenvolvimento sustentável, que é entendido, segundo o Relatório de Brundtland, como "um processo de mudança em que a exploração dos recursos, a direção dos investimentos, a orientação do desenvolvimento tecnológico e a mudança institucional estão todos em harmonia" para que as necessidades humanas possam ser satisfeitas atualmente e no futuro (WCDE, 1987). Entretanto, a dificuldade em sua implementação não está na simples concepção da nova alternativa, mas no fato de requerer uma série de modificações culturais e dos padrões de produção e consumo estabelecidos (SCHUMACHER, 2001).

Para tanto, as organizações, incluindo empresas, governos e organizações não governamentais (ONGs), terão de trabalhar em parceria, em meio a um processo de gestão, para que haja a mudança no paradigma de desenvolvimento (PEATTIE; CHARTER, 2003). Desse modo, na medida em que um conjunto de atores sociais se torna atuante na sociedade, poderá contribuir direta ou indiretamente para essa nova perspectiva (BUARQUE, 2008; CANEPA, 2007).

Nesse contexto, o Estado deve garantir os direitos civis, sociais e políticos de todos os cidadãos, bem como elaborar políticas públicas, programas de educação ambiental e de incentivo ao desenvolvimento sustentável. Já as empresas devem desenvolver seus negócios levando em consideração os aspectos ambientais, sociais e econômicos e elevando, assim, suas preocupações para além do lucro. E, por fim, todos os indivíduos devem agir como cidadãos conscientes da responsabilidade em relação às outras pessoas e ao meio ambiente (SILVA, 2011).

Considerando que o padrão de consumo é um dos principais geradores dos problemas ambientais (FOLADORI, 2005; LENZEN et al., 2007), o indivíduo deve buscar reduzir os seus impactos negativos (e os de outros consumidores), incorporando essa atitude na sua tomada de decisão e na formação do seu comportamento de compra. Partindo da premissa da ética da responsabilidade de Jonas (1992), o homem é um ser que tem responsabilidades (reconhecido como dever) e o seu interesse deve condizer com o interesse dos outros membros, visto que preservar a natureza envolve preservar o ser humano (RAMALHO; SANTOS, 2010).

Nesse sentido, o consumidor engajado pode ser visto como um novo ator social. Consciente das implicações dos seus atos de consumo, passa a compreender que está ao seu alcance exigir que as dimensões sociais, culturais e ecológicas sejam consideradas pelos setores produtivo, financeiro e comercial em seus modelos de produção, gestão, financiamento e comercialização (RODRIGUES et al., 2011).

Para Gurau e Ranchhod (2005), o consumo consciente é a principal manifestação de responsabilidade social do cidadão, podendo ser entendida como uma contribuição direta para o desenvolvimento social e a criação de uma sociedade mais justa e igualitária. O consumidor deve ser incentivado a fazer com que o seu ato de consumo seja também um ato de cidadania, dando prioridade, no momento de comprar, a produtos e/ou serviços que satisfaçam suas necessidades sem prejudicar o bem-estar da coletividade, seja ela atual ou futura.

\subsection{Consumo consciente e o comportamento do consumidor}

Em meio à perspectiva de mercado atual, em diferentes processos interacionais que surgem, entender e satisfazer necessidades e desejos dos indivíduos a partir de uma relação em que a troca seja a essência fundamental do processo traduz o conceito de marketing até então mais difundido. A compreensão e interação das empresas com esses consumidores, assim como a busca pela superação de suas expectativas em relação à compra, podem ser consideradas o 
principal desafio dos profissionais da área. Para uma melhor atuação desses profissionais, é necessário conhecer as características dos consumidores, com base em seu comportamento.

A disciplina de comportamento do consumidor contempla, justamente, os estudos acerca dos processos envolvidos no momento em que os indivíduos selecionam, compram, usam e descartam produtos (SOLOMON, 2011). Sendo assim, convencionou-se interpretar o processo de compra por meio de um modelo que apresenta variáveis relacionadas às etapas e aos fatores internos e externos que influenciam os indivíduos a adquirir um produto em detrimento de outros. Tal modelo consiste em cinco etapas: (1) necessidade, (2) busca por informações, (3) avaliação das alternativas, (4) decisão e (5) pós-compra (KOTLER; ARMSTRONG, 2007).

Concomitantemente a essas etapas, encontram-se os fatores internos e externos ao indivíduo que influenciam diretamente o seu processo de tomada de decisão. Tais fatores envolvem aspectos psicológicos, sociais, culturais e pessoais, devendo ser incorporados pelas organizações na definição de suas ações estratégicas. Diante desse contexto, os indivíduos tendem a se comportar de acordo com uma combinação de fatores que influenciam o comportamento ao longo de suas vidas, ou seja, sua conduta é modificada diante de interpretações que são moldadas com o passar do tempo.

Um exemplo de como tais fatores podem se combinar e alterar o padrão de consumo de determinado grupo social pode ser observado na discussão acerca da questão ambiental, ocasionada pela escassez de recursos, pela poluição intensa, por desastres ambientais, pela maior regulamentação por parte do governo etc. (KOTLER; ARMSTRONG, 2007). Tais acontecimentos, presenciados por diversas gerações de consumidores, levam a uma nova percepção acerca do mundo e resultam na interação empresa-sociedade pautada na necessidade e nos desejos por produtos que forneçam aos consumidores a opção de poder agir a favor de uma sociedade mais comprometida com questões sociais e ambientais (SOLOMON, 2011).

Nesse sentido, entender como as mudanças sociais interferem na formação de valores, crenças e atitudes das pessoas e, consequentemente, no seu perfil enquanto consumidor se torna relevante tanto para os líderes das grandes corporações quanto para os gestores públicos que visam seguir em direção ao desenvolvimento sustentável. Assim, ao levar em consideração que toda a sociedade é responsável por essa nova forma de desenvolvimento, é possível conceder maior foco para as questões individuais, visto que a coletividade é resultado de um conjunto de indivíduos e que, portanto, pode facilitar o alcance de determinado objetivo.

Nas discussões sobre a temática, continuamente surgem novas perspectivas quanto às maneiras de buscar essa nova forma de desenvolvimento. Como resultado da conferência mundial Eco-92, uma das mais importantes a esse respeito, surgiu a Agenda 21, um marco das questões pertinentes à sustentabilidade. Esse documento elenca, em seus 40 capítulos, questões pertinentes para o desenvolvimento sustentável, tais como mudanças na forma de atuação do governo, das organizações com e sem finalidade lucrativa e da população, na busca por uma "operacionalização" desse desenvolvimento. Sabe-se, como discutido anteriormente, que é necessária a inter-relação de alguns atores sociais, como governo, empresas e demais integrantes da sociedade, para o alcance desse objetivo em comum (SILVA, 2012).

Ao focar as questões individuais dentro de um contexto mais amplo, percebe-se que a capacidade de escolha de cada indivíduo sugere alternativas para a mudança na forma de atuação junto ao meio ambiente e às questões da sociedade. Entendendo que, de forma alguma, o ato de consumir pode deixar de existir, o consumo consciente efetiva-se ao considerar os impactos por ele provocados, buscando maximizar os positivos e minimizar os negativos de acordo com os princípios da sustentabilidade (INSTITUTO AKATU, 2010). Esse fato é corroborado por Fabi et 
al. (2010, p. 6) quando mencionam que o consumo consciente pode ser considerado como "o ato ou decisão de compra ou uso de serviços, de bens industriais ou naturais, praticado por um indivíduo levando em conta o equilíbrio entre satisfação pessoal, as possibilidades ambientais e os efeitos sociais de sua decisão". Sob uma ótica mais ampla, Silva e Menk (2014, p. 4) conceituam o consumo consciente como:

A prática humana que leva em consideração seus impactos sobre o meio, não por pressões que possam ocorrer, mas como reflexo de um processo reflexivo e sentimento de pertencimento do ser no meio, onde suas ações estão direcionadas para a busca por resultados coletivos.

Nesse sentido, como forma de prevenir o colapso da civilização humana, a mudança no padrão de consumo dominante, ou seja, no comportamento de consumo dos indivíduos, e o emergir de um novo padrão mais consciente indicam uma alternativa para a mudança na maneira como se visualiza a questão da sustentabilidade (ASSADOURIAN, 2010). Assim, essa nova prática pode ser entendida como uma relação de mutualidade, ou seja, como uma nova forma de atuação em todas as esferas, que, para Furriela (2001, p. 47), "depende da conscientização dos indivíduos da importância de tornarem-se consumidores responsáveis".

Na compreensão ampla da maneira como cada indivíduo deve atuar em relação ao consumo consciente, na visão de Silva e Gómez (2010), torna-se necessário considerar características como: a cultura na qual a sociedade do consumo está envolvida, o estilo de vida adotado, o poder aquisitivo, as questões éticas assumidas por cada um e a educação da sociedade, aspectos estes que estão relacionados diretamente com o estudo do comportamento do consumidor e que facilitam todo o processo de definição estratégica das organizações com relação às práticas de marketing.

Diante da dinâmica vivenciada pela sociedade do consumo (BAUDRILLARD, 2007), em que há uma grande oferta de produtos e um desordenado incentivo pelo consumo, faz-se necessário estudar cada uma dessas características a fim de compreender melhor essa temática. Isso permitirá que as organizações que assumem seu papel de responsabilidade nesse processo trabalhem com uma nova perspectiva mercadológica, mais envolvida com os valores e o comportamento apresentados pelos seus consumidores.

Assim sendo, percebe-se, segundo Feital et al. (2008, p. 5), que "a mudança de comportamento do consumidor é um processo que exige a sensibilização e mobilização social e, para esse processo, os meios de comunicação são fundamentais atuando junto ao público, mobilizando a consciência e ação dos consumidores". Nesse relacionamento entre empresas, governos e consumidores, entende-se que, assumindo esse novo comportamento, o indivíduo melhora sua atuação na sociedade e contribui para o desenvolvimento sustentável.

\section{PROCEDIMENTOS METODOLÓGICOS}

Para atender aos objetivos propostos, foi realizado um estudo descritivo e quantitativo, embasado em pesquisa bibliográfica e de campo (RICHARDSON et al., 2008). O universo selecionado foi a população do Recife, Pernambuco, e a coleta de dados foi realizada com as seis Regiões Político-Administrativas (RPAs) da cidade. Por meio de abordagem probabilística por acessibilidade, considerando o gênero e a faixa etária, a amostra foi de 601 questionários, com erro de $4 \%$ e $95 \%$ de grau de confiança.

Após coletados, os dados obtidos foram tabulados e analisados no software SPSS 17.0, instalado no laboratório do Programa de Pós-Graduação em Administração (PROPAD) da Univer- 
sidade Federal de Pernambuco (UFPE). Os dados originários deste estudo foram, inicialmente, analisados por Silva, Oliveira e Gomez (2013). Contudo, tal estudo carecia de uma análise multivariada e da utilização de estatísticas inferenciais, que permite maior confiabilidade dos dados, bem como desenvolvimento de inferências que anteriormente não foram feitas. A análise multivariada consiste em um agrupamento de métodos estatísticos que permite analisar medidas múltiplas para cada fenômeno observado simultaneamente (CORRAR; PAULO; DIAS FILHO, 2007). Tal análise auxilia a entender o comportamento de consumo consciente (ver Figura 1).

Figura 1 - Objetivos específicos $x$ técnicas estatísticas

\begin{tabular}{|c|c|}
\hline Objetivos específicos & Técnica(s) estatística(s) \\
\hline $\begin{array}{c}\text { Determinar o perfil dos entrevistados } \\
\text { de consumo consciente }\end{array}$ & Estatística descritiva \\
\hline $\begin{array}{c}\text { Apontar características da população recifense quanto à ideia } \\
\text { sumo sustentável }\end{array}$ & Análise fatorial \\
\hline $\begin{array}{c}\text { Verificar se fatores como gênero, escolaridade e renda influen- } \\
\text { ciam a conscientização da população quanto à prática do con- }\end{array}$ & Correlações e teste de hipóteses \\
\hline $\begin{array}{c}\text { Identificar possíveis contribuições dos consumidores recifen- } \\
\text { ses na busca pela mudança rumo ao desenvolvimento susten- } \\
\text { tável }\end{array}$ & $\begin{array}{c}\text { Interpretação dos dados obtidos a par- } \\
\text { tir da estatística descritiva e inferencial }\end{array}$ \\
\hline
\end{tabular}

Fonte: elaborado pelos autores (2014).

Neste estudo, como pode ser observado na Figura 1, o perfil dos entrevistados foi obtido a partir da estatística descritiva, utilizando principalmente a frequência das respostas. 0 segundo e terceiro objetivos específicos foram obtidos, respectivamente, a partir da análise fatorial e das correlações e do teste de hipóteses. A análise fatorial é uma técnica estatística que "permite detectar a existência de certos padrões subjacentes nos dados, de maneira que possam ser reagrupados em um conjunto menor de dimensões ou fatores" (CORRAR; PAULO; DIAS FILHO, 2007, p. 74); isto é, utilizou-se a análise fatorial para obter um número menor de fatores que caracterizam o comportamento de consumo dos recifenses. Para a análise da confiabilidade e validade dos dados, verificou-se a consistência interna do conjunto de itens das escalas por meio do alfa de Cronbach (CRONBACH, 1951).

Como forma de proporcionar maior confiabilidade à análise fatorial, foram realizados ainda outros dois testes: o Kaiser-Meyer-Olkin (KMO) e o de esfericidade de Bartlett. O KMO mede o grau de correlação parcial entre as variáveis e indica o grau de explicação dos dados a partir dos fatores encontrados na análise fatorial. Caso o KMO indique um grau de explicação inferior a 0,50, isso significa que os fatores encontrados não conseguem descrever satisfatoriamente as variações dos dados. Já o teste de esfericidade de Bartlett indica se existe relação suficiente entre os indicadores para aplicação da análise fatorial. Para que seja possível a aplicação da análise, recomenda-se que o valor de p (teste de significância) não ultrapasse 0,05 (HAIR et al., 2009).

Os testes de hipóteses, por sua vez, são procedimentos para calcular se a probabilidade da diferença entre duas médias (ou dois percentuais) é devida ao acaso (SOUZA, 2011). Para a realização dos testes de hipóteses, primeiramente, realizaram-se os testes de normalidade Kolmogorov-Smirnov (K-S) e Shapiro-Wilk (S-W) para verificar se os dados são não normais e averiguar se a hipótese nula pode ou não ser refutada. Considerando que os testes K-S e S-W indicam a não normalidade dos dados, visto que $p<0,05$, foi utilizado, posteriormente, o teste não paramétrico de Spearman para verificar as correlações. Dentre as correlações realizadas, destacam-se: (1) entre gênero e compra de produtos sustentáveis, (2) entre renda e compra de produtos sustentáveis, e (3) entre escolaridade e compra de produtos sustentáveis. 
A partir da interpretação dos dados obtidos com as estatísticas, tornou-se possível atingir o quarto objetivo específico proposto. Uma vez geradas as informações, utilizou-se o software Excel 2007 para elaborar tabelas para uma melhor apresentação dos dados encontrados.

A seguir, são expostas as análises e discussões dos resultados, apresentando-se, inicialmente, o perfil dos entrevistados, obtido por meio de estatística descritiva. Após, na subseção intitulada comportamento do consumidor consciente, apresentam-se os resultados da análise fatorial e correlação com o gênero, com o intuito de relatar as características da população recifense quanto à ideia de consumo consciente. As demais subseções buscam descrever os resultados obtidos com os testes de hipóteses, tentando evidenciar se gênero, escolaridade e renda impactam o comportamento de consumo consciente.

\section{APRESENTAÇÃO E DISCUSSÃO DOS DADOS}

A presente seção destaca os principais achados desta pesquisa.

\subsection{Perfil dos entrevistados}

Para que seja possível o reconhecimento dos comportamentos específicos da população recifense quanto ao consumo consciente, faz-se necessário identificar os aspectos envolvidos com a temática, tais como: faixa etária, renda familiar e escolaridade. Compreendendo de maneira relacionada esses aspectos, é possível verificar, de forma mais clara, qual é o perfil dessa população para, em seguida, identificar as características do consumo consciente.

A partir dos dados obtidos, foi possível observar que a renda predominante na cidade ( $27 \%$ da população) do Recife é de até dois salários mínimos, o que pode influenciar nas respostas apresentadas. Quanto ao gênero, a maioria da amostra é feminina, dado deve ser levado em consideração nas análises, já que, por ser, a priori, um gênero com maiores preocupações e maior sensibilidade que o masculino, esses indivíduos podem se sentir mais incomodados com as práticas insustentáveis atuais. A faixa etária da população estudada, em sua maioria, situa-se entre 20 e 39 anos, mostrando um perfil jovem que pode vir a se preocupar mais com o tema pesquisado.

Já quanto à escolaridade, aspecto que Silva e Gómez (2010) destacam como um dos que mais deve ser levado em consideração para a prática do consumo consciente ser efetivada. a maioria dos entrevistados $(30,3 \%)$ tem ensino superior incompleto. Esse perfil sugere a existência da possibilidade de uma preocupação maior com a busca por uma modificação em seu comportamento, já que, teoricamente, quanto mais informações são recebidas, mais politizado e consciente de suas práticas é o indivíduo-cidadão.

Quando questionados sobre a sua moradia, 57,9\% dos entrevistados dizem que moram com três ou quatro pessoas, e 57,2\% responderam que consideram sua residência um pequeno apartamento ou uma casa com quatro quartos ou menos. Essas informações sugerem que o perfil da população pode ser considerada homogêneo em suas características, facilitando as inferências que forem realizadas posteriormente.

Quando perguntados a respeito dos seus hábitos de transporte, 57,9\% dos entrevistados disseram que não dirigem. Esse fato pode estar relacionado com a renda da população pesquisada, como visto anteriormente, que é de até dois salários mínimos, o que indica que, com tal renda, os consumidores não têm condições de adquirir um automóvel. Esses indivíduos contribuem, assim, mesmo que de forma alheia à sua vontade, com a redução na quantidade de combustíveis fósseis que são consumidos nas cidades. 
Em relação aos hábitos de poupança, a maioria dos respondentes $(47,8 \%)$ respondeu que vive dentro das suas possibilidades, enquanto que $25,5 \%$ gastam toda a sua renda e $25,5 \%$ sempre economizam para o futuro. De forma complementar, buscando entender como os respondentes agiriam a partir de uma mudança em suas rendas, percebeu-se que $64,4 \%$ alegaram que, se suas rendas fossem maior, os produtos sustentáveis seriam privilegiados. Dessa informação, pode-se inferir que um dos motivos pelos quais a população não consome mais produtos sustentáveis consiste na renda que recebe.

Quanto ao estilo de vida dos participantes da pesquisa, percebeu-se que $40,6 \%$ dos entrevistados se consideram onívoros, que são aqueles que consomem todos os alimentos sem restrições, incluindo carne, frutos do mar, laticínios, vegetais e grãos. Esse tipo de dieta está em consonância com o perfil nacional, caracterizado pelo consumo todos os alimentos sem restrições. Com isso, percebe-se que as informações até então apresentadas mostram uma população jovem e com pouca renda.

\subsection{Comportamento do consumidor consciente}

Na tentativa de assimilar as características da população recifense quanto à ideia de consumo consciente que vem sendo trabalhada, buscou-se identificar alguns comportamentos que são desenvolvidos cotidianamente. Assim, para identificação do perfil desses consumidores de forma geral, concedeu-se destaque para os indicadores que estão melhor representados nos resultados. Para que o consumo consciente seja, de fato, praticado, é necessário que haja uma preocupação do consumidor com relação ao que será comprado, o que foi observado quanto à compra de alimentos e roupas, indicando que não há consumo incontrolável e despreocupado da população.

Quanto ao modo como o indivíduo vê o consumo, $77,7 \%$ consideram que a origem dos produtos que consumem é muito importante, pois sua produção pode ter causado danos para o meio ambiente e para a sociedade. Além disso, 74,4\% apontaram que só o governo não tem condições de garantir o equilíbrio da sociedade e direcionar questões como eliminação da pobreza e proteção ao meio ambiente, corroborando com a questão central de busca por um desenvolvimento sustentável, pois também as pessoas e as organizações em geral precisam atuar juntas para a promoção de uma sociedade mais responsável.

Observa-se que grande parte da população entrevistada consome, com frequência, carne $(41,8 \%)$, galinha $(40,3 \%)$, frutas e vegetais $(51,4 \%)$, o que corrobora as informações sobre a dieta apresentadas anteriormente. Quando se analisam esses aspetos, existe um ponto que deve ser observado: o consumo de produtos que necessitam de muita água para a sua produção, como é o caso da carne. Quanto mais se consome carne, maior o impacto sobre o meio ambiente com relação ao consumo de água e também a outros vários aspetos que são consequência da pecuária.

Sobre a utilização do transporte público, $46,8 \%$ dos respondentes utilizam-no sempre, o que pode estar relacionado com a baixa renda da população. Como se pode verificar, todas essas características proporcionam uma visão genérica de como se comportam esses consumidores. Como forma de garantir maior profundidade nos dados, as análises a seguir foram realizadas por meio de estatísticas inferenciais, que testam efetivamente a atuação desse ator quanto ao consumo consciente. Nesse sentido, inicialmente, para verificar a aplicabilidade dos questionamentos realizados, utilizou-se o alfa de Cronbach como teste de confiabilidade.

Utilizando o alfa de Cronbach, foi possível identificar que há relação entre as variáveis. A partir da Tabela 1, observa-se que os coeficientes não padronizados e padronizados são, respectivamente, 0,812 e 0,818, com base em 19 variáveis inseridas no questionário como um todo. Os 
valores apresentados demonstram a consistência das escalas utilizadas para aplicação da análise multivariada. Como forma de proporcionar uma maior confiabilidade à análise fatorial, foram realizados outros dois testes: o KMO e o de esfericidade de Bartlett.

Tabela 1 - Análise da confiabilidade estatística para utilização da análise fatorial

\begin{tabular}{|c|c|c|}
\hline \multicolumn{3}{|c|}{ Confiabilidade estatística } \\
\hline Alfa de Cronbach & Alfa de Cronbach baseado em itens padronizados & Número de itens \\
\hline $\mathbf{0 , 8 1 2}$ & 0,818 & 19 \\
\hline
\end{tabular}

É possível utilizar a análise fatorial no presente estudo, uma vez que foram identificados o valor de 0,862 para o KMO e p de 0,000 para o teste de esfericidade de Bartlett. A partir dessa análise, pode-se melhor caracterizar os aspectos relacionados com o consumo consciente e então definir a aplicação ou não de um comportamento individual nesse sentido. Assim sendo, com relação ao total de variância explicada, verifica-se que os fatores estão pouco relacionados, de modo que o modelo consegue explicar apenas $46,1 \%$ da variância dos dados, a partir de quatro fatores. Tais fatores são apresentados a seguir, na Tabela 2, destacando-se a maneira como estão articulados.

Tabela 2 - Matriz de Componentes Rotacionados

\begin{tabular}{|c|c|c|c|c|c|}
\hline \multirow{2}{*}{ Variáveis } & \multicolumn{5}{|c|}{ Componente } \\
\hline & 1 & 2 & 3 & 4 & \\
\hline Utiliza o verso das folhas de papel já utilizadas & 0,552 & \multirow{4}{*}{\multicolumn{4}{|c|}{ Práticas conscientes do indivíduo }} \\
\hline Leva em conta a proximidade & 0,654 & & & & \\
\hline $\begin{array}{c}\text { Preocupa-se em usar recursos de modo que não } \\
\text { tragam prejuízos }\end{array}$ & 0,654 & & & & \\
\hline Apoia campanhas de outras ações & 0,521 & & & & \\
\hline Planeja as compras de alimentos & & 0,666 & \multirow{3}{*}{\multicolumn{3}{|c|}{ Processo de compra consciente }} \\
\hline Pede nota fiscal & & 0,685 & & & \\
\hline Lê o rótulo antes da compra & & 0,558 & & & \\
\hline $\begin{array}{l}\text { Pratica e incentiva o consumo de produtos que } \\
\text { apoiem ações de inclusão }\end{array}$ & & & 0,707 & \multirow{3}{*}{\multicolumn{2}{|c|}{$\begin{array}{l}\text { Indivíduo socialmente } \\
\text { consciente/consciência } \\
\text { social do indivíduo }\end{array}$}} \\
\hline Mobiliza-se para incentivar as empresas & & & 0,747 & & \\
\hline Costuma deixar de comprar produtos de empresas & & & 0,571 & & \\
\hline Fecha a torneira enquanto escova os dentes & & & & 0,804 & \multirow{2}{*}{$\begin{array}{l}\text { Consciência } \\
\text { ambiental do } \\
\text { indivíduo/ } \\
\text { indivíduo am- } \\
\text { bientalmente } \\
\text { consciente }\end{array}$} \\
\hline Fecha o chuveiro & & & & 0,769 & \\
\hline Evita deixar lâmpadas acesas & & & & & \multirow{7}{*}{$\begin{array}{l}\text { Não correlacio- } \\
\text { nados }\end{array}$} \\
\hline Desliga os aparelhos quando não está usando & & & & & \\
\hline Planeja compra de roupas & & & & & \\
\hline Separa o lixo para reciclagem & & & & & \\
\hline Espera os alimentos esfriarem antes de guardar & & & & & \\
\hline $\begin{array}{c}\text { Procura passar as informações ao maior número } \\
\text { possível de pessoas }\end{array}$ & & & & & \\
\hline Não liga o ar-condicionado & & & & & \\
\hline
\end{tabular}

Método de extração: Análise do Componente Principal. Método de rotação: Varimax com Normalização Kaiser. A rotação foi convergida em seis interações. 
Essas informações estão relacionadas com a matriz de componentes após a rotação dos fatores. Com isso, justifica-se a organização dos dados em quatro fatores e melhor se estrutura a definição de características que facilitam a compreensão dessa prática de consumo consciente. A partir desse momento, é possível efetivar uma classificação mais precisa dos indicadores em cada um dos fatores, atribuindo nomenclaturas para cada fator de acordo com as características semelhantes dos indicadores pertencentes ao agrupamento.

O fator 1, categorizado como práticas conscientes do indivíduo, é composto dos atributos: utiliza o verso das folhas de papel já utilizadas; leva em conta a proximidade e facilidade de acesso entre locais de moradia, trabalho e estudo; preocupa-se em usar recursos de modo que não tragam prejuízos; e apoia campanhas de outras ações. $O$ fator 2 , categorizado como processo de compra consciente, é formado pelas variáveis: lê o rótulo antes da compra; planeja as compras de alimentos; e pede nota fiscal. Já o fator 3 , indivíduo socialmente consciente/consciência social do indivíduo, engloba os atributos: pratica e incentiva o consumo de produtos que apoiem ações de inclusão; mobiliza-se para incentivar as empresas; costuma deixar de comprar produtos de empresas como punição por terem feito algo prejudicial à sociedade. 0 fator 4 , por sua vez, nomeado de consciência ambiental do indivíduo/indivíduo ambientalmente consciente, é compõe dos indicadores: fecha a torneira enquanto escova os dentes; e fecha o chuveiro.

Identificadas as correlações e os fatores daí oriundos, optou-se por agrupar os comportamentos a fim de analisar a opinião dos entrevistados. Assim sendo, na Tabela 3, são apresentadas as frequências dos fatores, separadas pelo gênero dos entrevistados.

Tabela 3 - Cruzamento entre os fatores e o gênero

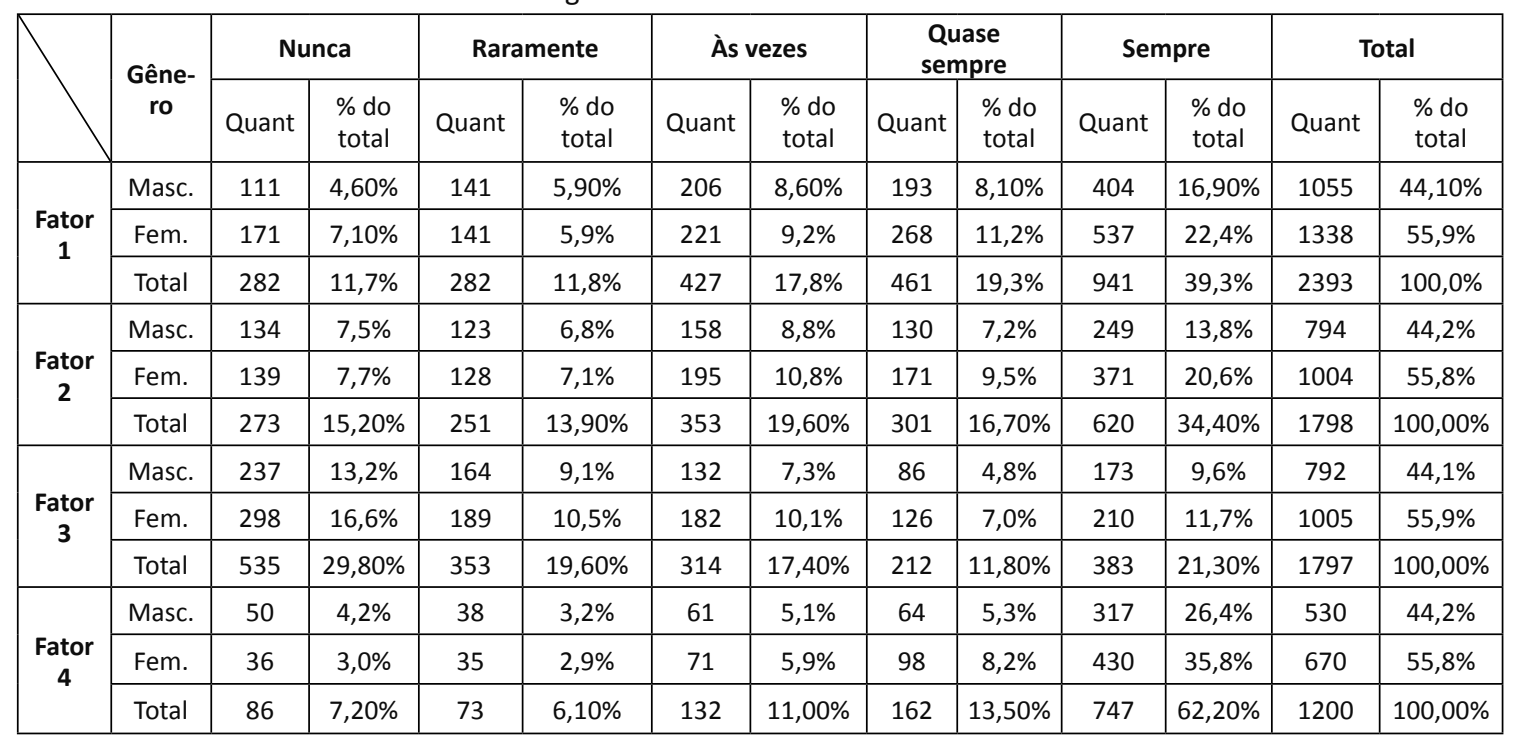

Porcentagens e totais são baseados nas respostas

A partir da Tabela 3, percebe-se que a maior parte dos entrevistados afirmou que quase sempre ou sempre adota comportamentos conscientes, exceto no que tange ao fator indivíduo socialmente consciente, caso em que $49,4 \%$ dos entrevistados afirmaram que nunca ou raramente praticam e incentivam o consumo de produtos que apoiem ações de inclusão, nunca ou raramente se mobilizam para incentivar as empresas e nunca ou raramente costumam deixar de comprar produtos de empresas como punição por terem feito algo prejudicial à sociedade. Isso demonstra que os recifenses, apesar de adotarem alguns comportamentos conscientes e de proteção ao meio ambiente, não são ativos no sentido de exigir das empresas a adoção de práticas sustentáveis. 
É possível observar, também, que 58,6\% dos entrevistados quase sempre ou sempre adotam práticas conscientes, visando utilizar os recursos de modo sem prejudicar o meio ambiente e a sociedade, além de valorizar e apoiar ações e campanhas beneficentes. Quanto ao processo de compra consciente, $51,10 \%$ dos entrevistados responderam que quase sempre ou sempre leem o rótulo dos produtos antes de comprá-los, planejam as compras de alimentos e pedem nota fiscal. Já em relação à consciência ambiental do indivíduo, 75,7\% dos entrevistados afirmaram fechar a torneira enquanto escovam os dentes e fechar o chuveiro enquanto tomam banho. Esses indicativos demonstram que os indivíduos evitam o desperdício e preocupam-se com a saúde de seus familiares e da sociedade.

Por fim, é importante salientar que não há diferença significativa entre os comportamentos dos homens e das mulheres. O predomínio das mulheres nas porcentagens da Tabela 4 , apresentada a seguir, reflete apenas a superioridade do número de mulheres entrevistadas em relação ao número de homens da amostra. Entretanto, para que haja uma melhor compreensão dos consumidores quanto à sua prática, faz-se necessário realizar alguns testes estatísticos que facilitem a identificação efetiva de como esses indivíduos se comportam. Para tanto, foram realizados o teste de hipóteses e correlações, objetivando evidenciar se aspectos como gênero, renda e escolaridade influenciam o comportamento de consumo.

\subsubsection{Teste de hipóteses}

\section{As mulheres compram mais produtos sustentáveis do que os homens?}

$H_{o}: \mu_{M}=\mu_{H} A$ média de mulheres que compram produtos orgânicos ou sustentáveis é igual à média de homens;

$H_{1}: \mu_{M} \neq \mu_{H} A$ média de mulheres que compram produtos orgânicos ou sustentáveis é diferente da média de homens.

Para responder a essa questão, o primeiro passo é realizar o teste de normalidade para verificar se os dados são não normais e averiguar se a hipótese nula pode ou não ser refutada.

Tabela 4 - Testes de normalidade Kolmogorov-Smirnov e Shapiro-Wilk

\begin{tabular}{|c|c|c|c|c|c|c|}
\hline \multicolumn{3}{|c|}{ Testes de normalidade } \\
\hline & \multicolumn{2}{|c|}{ Kolmogorov-Smirnov ${ }^{\text {a }}$} & \multicolumn{3}{c|}{ Shapiro-Wilk } \\
\hline & Estatística & df & Sig. & Estatística & df & Sig. \\
\hline $\begin{array}{c}\text { Gênero } \\
\begin{array}{c}\text { Comprou produtos feitos com } \\
\text { material reciclado }\end{array}\end{array}$ & 0,371 & 600 & 0,000 & 0,632 & 600 & 0,000 \\
\hline Comprou produtos orgânicos & 0,451 & 600 & 0,000 & 0,562 & 600 & 0,000 \\
\hline * Lilliefors Significance Correction & & 600 & 0,000 & 0,518 & 600 & 0,000 \\
\hline
\end{tabular}

Observando a Tabela 4, constata-se uma Sig. $<0,05$. Esse valor permite refutar a hipótese nula e aceitar com $95 \%$ de confiança a hipótese alternativa de que a média de mulheres que compram produtos orgânicos ou sustentáveis é diferente da média de homens. Seria interessante, também, saber se essa diferença entre as variáveis "gênero" e "compra de produtos sustentáveis e orgânicos" é intensa ou incipiente. Para tanto, será realizada a correlação entre as referidas variáveis por meio do teste de Spearman, visto que foi detectada a não normalidade dos dados.

De acordo com a Tabela 5, entende-se que a correlação entre as variáveis "gênero" e "compra de produtos elaborados com material reciclado" apresenta um efeito fraco $(0,29)$. Além 
disso, quando observado o valor da significância do coeficiente de correlação, nota-se que não há um relacionamento significativo entre as variáveis mencionadas, já que Sig. $>0,05$. No que diz respeito à correlação entre as variáveis "gênero" e "compra de produtos orgânicos", observou-se também uma correlação com efeito fraco ou inexistente $(-0,34)$.

Tabela 5 - Correlação de Spearman Rho

\begin{tabular}{|c|c|c|c|c|}
\hline \multirow{2}{*}{ Gênero } & Coeficiente de correlação & 1 & 0,029 & $-0,034$ \\
\cline { 2 - 5 } & Sig. (1-tailed) & - & 0,243 & 0,205 \\
\cline { 2 - 5 } & $\mathrm{N}$ & 600 & 600 & 600 \\
\hline \multirow{2}{*}{$\begin{array}{c}\text { Comprou pro- } \\
\text { dutos feitos } \\
\text { com material } \\
\text { reciclado }\end{array}$} & Coeficiente de correlação & 0,029 & 1 &, $363^{* *}$ \\
\cline { 2 - 5 } & Sig. (1-tailed) & 0,243 & & 0,000 \\
\hline $\begin{array}{c}\text { Comprou pro- } \\
\text { dutos orgâni- } \\
\text { cos }\end{array}$ & \begin{tabular}{c} 
Coeficiente de correlação \\
\cline { 2 - 5 }
\end{tabular} & $-0,034$ & 601 & 601 \\
\cline { 2 - 5 } & Sig. (1-tailed) & 0,205 & $0,363^{* *}$ & 1 \\
\cline { 2 - 5 } & $\mathrm{N}$ & 600 & 0,000 & \\
\hline
\end{tabular}

**Correlação é significante no nível 0,01 (1-tailed)

Ademais, a Sig. >0,05 implica a inexistência de relacionamento entre as variáveis. Em linhas gerais, observa-se, com base nas correlações apresentadas na Tabela 5, que são ínfimas as diferenças de gênero em relação à compra de produtos voltados à sustentabilidade. Esse achado se contrapõe aos resultados apresentados por Silva et al. (2012), os quais destacaram uma diferença notável entre os gêneros. Essa ínfima diferença detectada no teste de hipóteses pode ser corroborada por meio do cruzamento das variáveis, conforme a Tabela 6.

Tabela 6 - Cruzamento entre a compra de produtos sustentáveis e o gênero dos entrevistados

\begin{tabular}{|c|c|c|c|c|c|c|c|c|c|}
\hline \multicolumn{2}{|c|}{} & \multicolumn{4}{|c|}{ Compra de produtos recicláveis } & \multicolumn{3}{c|}{ Compra de produtos orgânicos } \\
\cline { 3 - 10 } & Sim & Não & NS/NR & Total & Sim & Não & NS/NR & Total \\
\hline \multirow{3}{*}{ Gênero } & Masculino & $18,20 \%$ & $14,50 \%$ & $11,50 \%$ & $44,20 \%$ & $16,20 \%$ & $18,00 \%$ & $10,00 \%$ & $44,20 \%$ \\
\cline { 2 - 10 } & Feminino & $21,70 \%$ & $18,30 \%$ & $15,80 \%$ & $55,80 \%$ & $22,50 \%$ & $21,30 \%$ & $12,00 \%$ & $55,80 \%$ \\
\cline { 2 - 10 } & Total & $39,90 \%$ & $32,80 \%$ & $27,30 \%$ & $100,00 \%$ & $38,70 \%$ & $39,30 \%$ & $22,00 \%$ & $100,00 \%$ \\
\hline
\end{tabular}

*Porcentagens equivalentes ao total de entrevistados

Na Tabela 6, pode-se notar que a maioria dos homens $(18,20 \%$ do total de entrevistados) e a maioria das mulheres ( $21,7 \%$ do total dos entrevistados) já compraram produtos recicláveis, indicando que não há diferença de gênero quanto à opção por produtos recicláveis. Já em relação à compra de produtos orgânicos, há uma pequena diferença entre homens e mulheres. $\mathrm{A}$ maioria das mulheres (22,5\% do total de entrevistados) opta pela compra de produtos orgânicos; no entanto, a diferença entre as que compram e as que não compram não é significativa, uma vez que $21,3 \%$ do total de entrevistados são mulheres que não consomem tal tipo de produto. 


\subsubsection{Correlação grau de escolaridade $x$ renda compra de produtos orgânicos $x$ compra de produtos feitos com material reciclado}

Há relação entre a compra de produtos sustentáveis e orgânicos e a renda e escolaridade dos entrevistados?

Para responder a essa questão, é preciso, primeiramente, realizar o teste de normalidade para verificar se os dados são não normais e se os dados são paramétricos ou não paramétricos. Dessa forma, é possível identificar qual correlação é mais adequada. Os testes de normalidade Kolmogorov-Smirnov (K-S) e Shapiro-Wilk (S-W) são apresentados na Tabela 7.

Tabela 7 - Testes de normalidade Kolmogorov-Smirnov e Shapiro-Wilk

\begin{tabular}{|c|c|c|c|c|c|c|}
\hline \multicolumn{7}{|c|}{ Testes de Normalidade } \\
\hline & \multicolumn{2}{|c|}{ Kolmogorov-Smirnov(a) } & \multicolumn{3}{c|}{ Shapiro-Wilk } \\
\cline { 2 - 7 } & Estatística & DF & Sig. & Estatística & df & Sig. \\
\hline Renda familiar & 0,507 & 601 & 0,000 & 0,317 & 601 & 0,000 \\
\hline Grau de escolaridade & 0,400 & 601 & 0,000 & 0,197 & 601 & 0,000 \\
\hline $\begin{array}{c}\text { Comprou produtos feitos } \\
\text { com material reciclado }\end{array}$ & 0,451 & 601 & 0,000 & 0,562 & 601 & 0,000 \\
\hline Comprou produtos orgânicos & 0,477 & 601 & 0,000 & 0,517 & 601 & 0,000 \\
\hline
\end{tabular}

* Lilliefors Significance Correction

A partir da Tabela 7, constata-se que os dados não são normais, tendo em vista que os testes K-S e S-W apresentaram uma Sig. $=0,000$. Esse resultado permite afirmar que os dados são não paramétricos, de modo que a correlação de Spearman Rho é a mais adequada.

A Tabela 8 exibe uma correlação negativa de efeito fraco ou inexistente entre as variáveis "renda familiar" e "comprou produtos orgânicos", apresentando um coeficiente de correlação de -0,164. Ademais, as variáveis "renda familiar" e "comprou produtos feitos com material reciclado" também possuem uma correlação negativa muito fraca ou quase inexistente, uma vez que o valor do coeficiente de correlação equivale a -0,074. O valor da significância para os coeficientes de correlação das variáveis analisadas é menor do que 0,05. Portanto, compreende-se que o relacionamento entre as variáveis mencionadas é, de fato, fraco/inexistente. Em termos práticos, entende-se que variações de rendas dos entrevistados não influenciam significativamente a opção pela compra de produtos sustentáveis e orgânicos. 
Tabela 8 - Correlação de Spearman Rho

\begin{tabular}{|c|c|c|c|c|c|c|}
\hline \multicolumn{7}{|c|}{ Correlação } \\
\hline & & & $\begin{array}{l}\text { Renda fa- } \\
\text { miliar }\end{array}$ & $\begin{array}{l}\text { Grau de escola- } \\
\text { ridade }\end{array}$ & $\begin{array}{l}\text { Comprou produtos } \\
\text { feitos com material } \\
\text { reciclado }\end{array}$ & $\begin{array}{l}\text { Comprou } \\
\text { produtos } \\
\text { orgânicos }\end{array}$ \\
\hline \multirow[t]{12}{*}{$\begin{array}{l}\text { Spear- } \\
\text { man Rho }\end{array}$} & \multirow{3}{*}{$\begin{array}{l}\text { Qual a sua } \\
\text { renda fami- } \\
\text { liar }\end{array}$} & $\begin{array}{c}\text { Coeficiente de } \\
\text { correlação }\end{array}$ & 1 & $0,423(* *)$ & $-0,074$ & $-0,164(* *)$ \\
\hline & & Sig. (2-tailed) & . & 0,000 & 0,070 & 0,000 \\
\hline & & $\mathrm{N}$ & 601 & 601 & 601 & 601 \\
\hline & \multirow[t]{3}{*}{$\begin{array}{l}\text { Grau de es- } \\
\text { colaridade }\end{array}$} & $\begin{array}{c}\text { Coeficiente de } \\
\text { correlação }\end{array}$ & $0,423(* *)$ & 1 & $-0,155(* *)$ & $-0,181(* *)$ \\
\hline & & Sig. (2-tailed) & 0,000 & . & 0,000 & 0,000 \\
\hline & & $\mathrm{N}$ & 601 & 601 & 601 & 601 \\
\hline & \multirow{3}{*}{$\begin{array}{c}\text { Comprou } \\
\text { produtos } \\
\text { feitos com } \\
\text { material } \\
\text { reciclado }\end{array}$} & $\begin{array}{c}\text { Coeficiente de } \\
\text { correlação }\end{array}$ & $-0,074$ & $-0,155\left(^{* *}\right)$ & 1 & $0,363(* *)$ \\
\hline & & Sig. (2-tailed) & 0,070 & 0,000 & . & 0,000 \\
\hline & & $\mathrm{N}$ & 601 & 601 & 601 & 601 \\
\hline & \multirow{3}{*}{$\begin{array}{l}\text { Comprou } \\
\text { produtos } \\
\text { orgânicos }\end{array}$} & $\begin{array}{c}\text { Coeficiente de } \\
\text { correlação }\end{array}$ & $-0,164(* *)$ & $-0,181(* *)$ & $0,363(* *)$ & 1 \\
\hline & & Sig. (2-tailed) & 0,000 & 0,000 & 0,000 & . \\
\hline & & $\mathrm{N}$ & 601 & 601 & 601 & 601 \\
\hline
\end{tabular}

Outra correlação pode observada entre as variáveis "grau de escolaridade" e "compra de produtos orgânicos". Nesse caso, constatou-se uma correlação de efeito fraco, que pode ser visualizada nos valores $-0,181$ e $p<0,05$. Ao correlacionar "grau de escolaridade" e "compra de produtos elaborados com material reciclado", verificou-se também um efeito fraco $(-0,155)$. Ambas as situações permitem afirmar que o grau de escolaridade dos participantes do estudo não influencia sua decisão de compra por produtos orgânicos

Duas últimas correlações tratam, respectivamente, da relação entre as variáveis "grau de escolaridade" e "renda" e entre as variáveis "compra de produtos elaborados com material reciclado" e "compra de produtos orgânicos". Na primeira situação, observou-se uma correlação positiva com efeito moderado, o qual é expresso nos valores 0,423 e Sig. $<0,05$. A partir desse achado, entende-se que as vaiáveis "grau de escolaridade" e "renda" se influenciam, de modo que, quando uma aumenta, a outra também aumenta e vice-versa. Já entre "compra de produtos elaborados com material reciclado" e "compra de produtos orgânicos", constatou-se uma correlação positiva de efeito moderado, pois o coeficiente de correlação apresenta um valor de 0,363. Nessa perspectiva, percebe-se que as pessoas que compram produtos advindos de materiais recicláveis são propensas à compra de produtos orgânicos.

A partir de todas as considerações que foram realizadas e de todas as evidências apresentadas, entende-se que, de acordo com os aspectos teóricos no que se refere à busca por uma maior contribuição para o desenvolvimento sustentável, e considerando que o ser consciente é inerente à prática humana na sociedade (SILVA; MENK, 2014), identificou-se que o recifense não apresenta ter consciência em seus comportamentos, mas assume uma posição de estar consciente, necessitando de uma estrutura melhor organizada e da atuação de outros atores que consigam estimular uma mudança.

Observando a relação entre os aspectos empíricos e teóricos, percebe-se que muitas ações ainda precisam ser realizadas por outros atores sociais, para que o consumidor, como aquele que se preocupa com seus impactos de consumo, possa incorporar uma nova visão de 
atuação e passe a se comportar sob uma nova ótica (SANTOS et al., 2008; SILVA; GÓMEZ, 2010; SILVA et al., 2012). Acredita-se, assim, que uma melhor construção de relações entre esses atores estimularia uma mudança para uma atuação mais consciente da população e permitiria que a prática de consumo se tornasse sustentável.

\section{CONSIDERAÇÕES FINAIS}

Considerando a necessidade de uma reestruturação na maneira como atuam diversos atores na sociedade, dentre os quais estão os consumidores enquanto aqueles que podem interagir diretamente com as organizações, seja para movimentar o sistema econômico ou para punir aquelas que não estejam de acordo com os padrões de responsabilidade social empresarial, percebe-se que esses consumidores necessitam se mostrar mais conscientes em seus atos (no sentido responsável) para que os impactos sobre o meio e a coletividade sejam minimizados.

Em meio a esse contexto, a presente pesquisa, ao propor a análise de como se comporta o consumidor recifense quanto ao consumo consciente, buscou não apenas destacar uma prática de consumo com relação ao que Solomon (2011) destaca quanto à compra, ao uso e ao descarte, mas também entender como o consumidor faz parte do meio. $O$ sistema em que o indivíduo está inserido, muitas vezes, impõe uma atuação feroz quanto ao pensamento capitalista, incentivando continuamente sentimentos negativos (SILVA; GÓMEZ, 2010). Contudo, esse aspecto não, necessariamente, precisa ser seguido pela população.

Nessa perspectiva, acredita-se que o artigo atendeu ao que se propôs, embora tenha ressaltado uma incompatibilidade entre a perspectiva almejada a práxis individual. De acordo com as considerações realizadas e com as estatísticas testadas, é possível afirmar que o consumidor do Recife mostra não ter consciência na maioria de suas ações, ainda que em alguns casos, como quanto à necessidade de reduzir o consumo de água e energia, o consumidor tenha essa consciência, assumindo estar consciente de suas ações. Isso pode ser justificado, segundo Silva e Menk (2014), uma vez que falta um contexto estrutural que embase esses comportamentos mais conscientes por parte da população. Sob outra ótica que não a econômica, é possível, entretanto, adotar uma mudança de pensamento.

No contexto estudado, percebe-se que nem a escolaridade nem a renda conseguiram estimular uma tendência positiva ao consumo consciente de parte da população, fato que é, muitas vezes, destacado como preponderante (DOBSON, 2003). Desse modo, o que falta ser observado? Faltam políticas públicas e educacionais mais eficazes, maior engajamento das empresas ou maior conscientização da população, que, politizada, conseguiria contribuir nesse sentido? Em meio a um processo reflexivo, muitos atores precisam atuar considerando que um conjunto de mudanças individuais deve ser incentivado continuamente.

Por fim, ressalta-se que a principal limitação deste estudo está em não agregar todos os indicadores inerentes aos instrumentos de avaliação de consumo identificados. Tendo isso em vista, futuras pesquisas devem buscar tornar homogêneos os indicadores utilizados e entender as variáveis que influenciam a prática ou não do consumo consciente. 


\section{REFERÊNCIAS}

ASSADOURIAN, E. Ascensão e queda das culturas de consumo. In: Worldwatch Institute. Estado do Mundo, 2010: estado do consumo e o consumo sustentável. Salvador: Uma Ed. 2010.

BARBIERI, J. C., DIAS, M. Logística Reversa como instrumento de programas de produção e consumo sustentáveis, Revista Tecnologística, São Paulo, ano 4, n. 77, p. 58-69, abr. 2002.

BAUDRILLARD, J. A sociedade de consumo. Lisboa: Arte \& Comunicação. 2007.

BUARQUE, S. C. Construindo o desenvolvimento local sustentável. 4. ed. Rio de Janeiro: Garamond, 2008.

CANEPA, C. Cidades sustentáveis: o município como lócus da sustentabilidade. São Paulo: RCS Editora, 2007.

CORRAR, L. J.; PAULO, E.; DIAS FILHO, J. M. Análise Multivariada. São Paulo: Atlas, 2007.

CRONBACH, L. J. Coefficient alpha and the internal structure of tests, Psychometrika, v. 16, n. 3, p. 297-334., set. 1951.

DOBSON, A. Citizenship and the Environment. Oxford: Oxford University Press, 2003.

ELKINGTON, J. Canibais com garfo e faca. São Paulo: Makroon Books, 2001.

FABI, M. J. S.; LOURENÇO, C. D. S.; SILVA, S. S. Consumo Consciente: a atitude do cliente perante o comportamento sócio-ambiental empresarial. In: ENCONTRO DE MARKETING DA ANPAD, 4., 2010, Florianópolis. Anais... Florianópolis: ANPAD, 2010.

FECOMERCIO-PE. Recifense otimista com a economia. Disponível em: <http://www. fecomercio-pe.com.br/economia/1773recifense-otimista-com-a-economia.html>. Acesso em: 22 dez. 2014.
FEITAL, J. C. C. et al. O consumo consciente da água: um estudo do comportamento do usuário doméstico. In: ENCONTRO DE MARKETING DA ANPAD, 3., 2008, Curitiba. Anais... Curitiba: ANPAD, 2008.

FOLADORI, G. Por uma sustentabilidad alternativa. Uruguai: Colección Cabichui, 2005.

FRANCO, M. A. R. Planejamento ambiental para a cidade sustentável. São Paulo: Annablume: FAPESP, 2001.

FURRIELA, R. B. Educação para o Consumo Sustentável. In: MINISTÉRIO DA EDUCAÇÃO. Ciclos de Palestras sobre o Meio Ambiente. Brasília: MEC, 2001. p. 47-55.

GURAU, C.; RANCHHOD, A. International Green Marketing: A Comparative Study of British a Romanian Firms. International Marketing Review, v. 22, n. 5, p. 547-561, 2005.

HAIR JR, J. F. et al. Análise Multivariada de Dados. 6. ed. Porto Alegre: Bookman, 2009.

INSTITUTO AKATU. 0 que é Consumo Consciente? Disponível em: <http://www. akatu.org.br/consumo_consciente/oque>. Acesso em: 24 jul. 2010.

INSTITUTO BRASILEIRO DE GEOGRAFIA E ESTATÍSTICA (IBGE). Perfil da população recifense. 2009. Disponível em: <http://www. ibge.gov.br/home/>. Acesso em: 13 fev. 2011.

JONAS, H. O princípio da vida. Fundamentos para uma biologia filosófica. Tradução de Carlos Almeida Pereira. Petrópolis: Vozes, 1992.

KOTLER, P.; ARMSTRONG, G. Princípios de Marketing. São Paulo: Pearson Prentice Hall, 2007.

LENZEN, M. et al. Shared producer and consumer responsibility: Theory and practice. Ecological Economics, p. 27-42, 2007.

PEATTIE, K.; CHARTER, M. Green marketing. In: BAKER, M. (Ed.). The marketing book. Gram Britannia: Butter Wealth. 2003. 
RAMALHO, A. M. C.; SANTOS, J. G. Ética, Responsabilidade e Consumo Sustentável: uma aproximação necessária. In: ENCONTRO DA ANPPAS, 5., 2010, Florianópolis. Anais... Florianópolis: ANPPAS, 2010.

RICHARDSON, R. J. et al. Pesquisa Social: métodos e técnicas. 3. ed. São Paulo: Atlas, 2008.

RODRIGUES, A. R. et al. Marketing Verde e Consumo Consciente: Segmentando o Mercado de Lavras/MG. In: ENCONTRO DA ANPAD, 35., 2011, Rio de Janeiro. Anais... Rio de Janeiro: ANPAD, 2011.

ROMEIRO, M. C. Um estudo do comportamento do consumidor ambientalmente favorável: uma verificação na região do $A B C$ paulista. 2006.358f. Tese (Doutorado em Administração) - Universidade de São Paulo, São Paulo, 2006.

SACHS, I. Rumo à ecossocioeconomia: Teoria e prática do desenvolvimento. São Paulo: Cortez, 2007.

SANTOS, T. C. S. et al. Movimento do Consumo Consciente: do Cidadão Consumidor ao Consumidor Cidadão? In: ENCONTRO DE ADMINISTRAÇÃO, POLÍTICA E GOVERNANÇA, 6., 2008, Salvador. Anais... Salvador: EnAPG, 2008.

SCHUMACHER, E. F. Lo pequeño es hermoso. Espana: Tursen S.A, 2001.

SEYFANG, G. Ecological citizenship and sustainable consumption: examining local organic food networks. Journal of Rural Studies, n. 22, p. 383-395, 2006.

SILVA, M. E.; OLIVEIRA, A. P. M.; GOMEZ, C. R. $P$. Indicadores de Consumo Consciente: uma avaliação do recifense sob a ótica do Consumo Sustentável. RECADM: Revista Eletrônica de Ciência Administrativa, v. 12, p. 39-56, 2013.

SILVA, M. E. A contribuição de práticas empresariais responsáveis para o consumo sustentável no varejo de supermercados: 0 caso Walmart Brasil. 2011. 137 f. Dissertação (Mestrado em Administração) - Universidade Federal de Pernambuco, Recife. 2011.

SILVA, M. E. Consumo Sustentável: A Articulação de um constructo sob a perspectiva do desenvolvimento sustentável. Revista Eletrônica de Ciências Administrativas (RECADM), v. 11, n. 2, p. 217-232, 2012.

SILVA, M. E. et al. Perfil de Consumo Consciente por meio de atitudes e comportamentos individuais: Um estudo com a população do Recife/PE. PMKT: Revista Brasileira de Pesquisas de Marketing, Opinião e Mídia, v. 10, p. 37-43, 2012.

SILVA, M. E.; GÓMEZ, C. P. Consumo Consciente: O papel contributivo da educação. Reuna, Belo Horizonte, v. 15, n. 3, p. 43-54. 2010.

SILVA, M. E.; MENK, T. F. A prática do consumo e os níveis de consciência: o consumo consciente sob a Filosofia de Hegel. Espacios, Caracas, v. 35, n. 4, p. 173-194, 2014.

SOLOMON, M. R. Comportamento do Consumidor. Bookman: Porto Alegre, 2011.

SOUZA, B. C. Testes de Hipóteses. (Notas de aulas - Programa de Pós-Graduação de Administração na Universidade Federal de Pernambuco), 2011.

WORLD COMMISSION ON ENVIRONMENT AND DEVELOPMENT. Report Our common future. Genebra, 1987. Disponível em: <http://www. un-documents.net/wced-ocf.htm.>. Acesso em: 13 jan. 2012. 